\title{
An eye for detail: an event-related potential study of the rapid processing of fearful facial expressions in children.
}

Citation for published version (APA):

Vlamings, P. H. J. M., Jonkman, L. M., \& Kemner, C. (2010). An eye for detail: an event-related potential study of the rapid processing of fearful facial expressions in children. Child Development, 81(4), 13041319. https://doi.org/10.1111/j.1467-8624.2010.01470.x

Document status and date:

Published: 01/01/2010

DOI:

10.1111/j.1467-8624.2010.01470.x

Document Version:

Publisher's PDF, also known as Version of record

\section{Document license:}

Taverne

\section{Please check the document version of this publication:}

- A submitted manuscript is the version of the article upon submission and before peer-review. There can be important differences between the submitted version and the official published version of record.

People interested in the research are advised to contact the author for the final version of the publication, or visit the DOI to the publisher's website.

- The final author version and the galley proof are versions of the publication after peer review.

- The final published version features the final layout of the paper including the volume, issue and page numbers.

Link to publication

\footnotetext{
General rights rights.

- You may freely distribute the URL identifying the publication in the public portal. please follow below link for the End User Agreement:

www.umlib.nl/taverne-license

Take down policy

If you believe that this document breaches copyright please contact us at:

repository@maastrichtuniversity.nl

providing details and we will investigate your claim.
}

Copyright and moral rights for the publications made accessible in the public portal are retained by the authors and/or other copyright owners and it is a condition of accessing publications that users recognise and abide by the legal requirements associated with these

- Users may download and print one copy of any publication from the public portal for the purpose of private study or research.

- You may not further distribute the material or use it for any profit-making activity or commercial gain

If the publication is distributed under the terms of Article $25 \mathrm{fa}$ of the Dutch Copyright Act, indicated by the "Taverne" license above, 


\title{
An Eye for Detail: An Event-Related Potential Study of the Rapid Processing of Fearful Facial Expressions in Children
}

\author{
Petra H. J. M. Vlamings and \\ Lisa M. Jonkman \\ Maastricht University
}

\author{
Chantal Kemner \\ Maastricht University and University \\ Medical Center Utrecht
}

\begin{abstract}
There is converging evidence for the presence of a fast subcortical face-processing route that operates on global face characteristics in the mature brain. Until now, little has been known about the development of such a route, which is surprising given suggestions that this fast subcortical face-processing route might be affected in neurodevelopmental disorders such as autism. To address this, early visual event-related potentials to pictures of fearful and neutral faces containing detailed or global information in 3- to 4-yearold $(n=20)$, 5- to 6-year-old $(n=25)$, and 7- to 8-year-old $(n=25)$ children were compared. In children, emotional processing was driven by detailed information. Developmental effects are discussed in terms of maturation of the fast subcortical face-processing route as well as an increase in experience with facial expressions with age.
\end{abstract}

Decoding the emotional content of a face is an important skill in daily life because it helps to evaluate the state and the intentions of others. Given that facial expressions like fear, anger, or threat may be signals of potential danger, it is plausible that the detection and processing of emotional expression proceeds very fast. Several authors have investigated what information the visual system extracts to decode emotional expressions so rapidly (Holmes, Winston, \& Eimer, 2005; Pourtois, Dan, Grandjean, Sander, \& Vuilleumier, 2005; Vuilleumier, Armony, Driver, \& Dolan, 2003; Winston, Vuilleumier, \& Dolan, 2003). Visual information that enters our visual system consists of luminance variations, which occur in a wide range of so-called spatial frequencies and can be expressed in cycles per degree (cpd) of visual angle (e.g., De Valois \& De Valois, 1988; Goldstein, 1999). Lower spatial frequencies (LSF) represent the large-scale variations, that is, coarse visual information such as shading or large contours, as well as the global configuration of the face (e.g., distance between eyes, eyebrows and mouth). High spatial frequencies (HSF)

The authors gratefully thank Sabine Koenraads, Pia Jansen, Anne Hermans, and Eveline Eerdekens for helping with the data collection.

Correspondence concerning this article should be addressed to Petra H. J. M. Vlamings, Cognitive Neuroscience Department, Developmental Cognitive Neuroscience Section, Faculty of Psychology and Neuroscience, University of Maastricht, PO Box 616, 6200 MD Maastricht, Netherlands. Electronic mail may be sent to p.vlamings@psychology.unimaas.nl. represent tighter gradients of luminance changes, that is, fine visual information (sharp edges, contours of features such as the mouth, eyes, wrinkles, and so on; Goffaux \& Rossion, 2006; Morrison \& Schyns, 2001).

By varying the spatial frequency content of a stimulus or image (by filtering out either high or low frequency information), one can study the difference in processing of this information (e.g., De Valois \& De Valois, 1988; Goldstein, 1999).

Behavioral studies have provided evidence for differential sensitivity to HSF and LSF content of emotional expressions for face recognition or identification in adults. For instance, it has been shown that participants use LSF information to categorize rapidly emotional expressions, whereas HSF information seems to be most important for the success with which one can explicitly rate emotional expressiveness (or intensity), a process that may proceed at a slower time-scale (Schyns \& Oliva, 1999; Vuilleumier et al., 2003; Deruelle \& Fagot, 2005; however, see Goren and Wilson, 2006, for different effects using synthetic faces). In addition, the LSF components of faces are critical to the production of rapid behavioral or attentional responses toward fearful facial expressions (Holmes, Green, \& Vuilleumier, 2005).

(C) 2010, Copyright the Author(s)

Journal Compilation (C) 2010, Society for Research in Child Development, Inc. All rights reserved. 0009-3920/2010/8104-0019 
Several authors have hypothesized that the rapid processing of fear occurs through a subcortical route in the brain that rapidly processes fear based on LSF information (Pourtois et al., 2005; Vuilleumier et al., 2003; Winston et al., 2003). This route starts at the ganglion cells in the retina. There are two cell types in the retina that are differentially sensitive to HSF and LSF, respectively: parvocellular (small receptive fields) and magnocellular neurons (large receptive fields). Several studies have indicated that although parvocellular and magnocellular neurons respond to an overlapping range of SFs, parvocellular neurons are preferentially tuned (most active) to HSF, whereas magnocellular neurons are more sensitive to LSF information (Enroth-Cugell \& Robson, 1966). Because the conduction velocity of axons of the parvocellular system is lower compared to the magnocellular system (see Hess, 2004), signals from the parvocellular system are transmitted more slowly compared to the magnocellular system (see for review Skottun \& Skoyles, 2007). The amygdala, a key structure for emotion processing, receives direct input from subcortical regions (tectum and pulvinar) that primarily receive retinal magnocellular input (Pourtois et al., 2005; Vuilleumier et al., 2003; Winston et al., 2003). It has been proposed that this type of subcortical input would enable the amygdala to rapidly process facial expressions based on LSF and to provide quick signals about for example fear-related stimuli (Johnson, 2005; Pourtois et al., 2005; Vuilleumier et al., 2003; Winston et al., 2003).

Two functional magnetic resonance imaging (fMRI) studies indeed provided evidence for this and found that the amygdala and connected subcortical regions are primarily sensitive to low spatial frequency information: Enhanced activity to emotional expressions in the amygdala and other subcortical structures was found only for faces containing LSF, but not HSF, information (Vuilleumier et al., 2003; Winston et al., 2003). Similar effects were found in the fusiform gyrus, a cortical structure specifically involved in the visual processing of faces (Vuilleumier et al., 2003; Winston et al., 2003). Furthermore, two event-related brain potential (ERP) studies in adults found that rapid effects of emotion in visual regions were primarily mediated by LSF information (Pourtois et al., 2005; Vlamings, Goffaux, \& Kemner, 2009). Based on these findings, a rapid, subcortical route (tectopulvinar-amygdala pathway) for facial expression processing has been proposed that operates on LSF information and modulates activity in visual cortical areas in which emotional signals are further processed (e.g., Le Doux, 1996; Vuilleumier et al., 2003; see for review Johnson, 2005). This fast subcortical face-processing route is seen as a "quick and dirty" route that extracts emotion based on global face characteristics or low spatial frequencies but not detailed information or HSF, which are processed through the "slower cortical route" (Johnson, 2005; Pourtois et al., 2005; Vuilleumier et al., 2003; Winston et al., 2003). Although the above-mentioned studies solely tested the role of SF in fear-related processing, this does not exclude the possibility that other types of facial expressions (e.g., threat-related) might also be processed by this subcortical face-processing route making use of LSF information. In addition, it is not known to what extent this (LSF) route distinguishes between different facial expressions (e.g., fear and surprise).

In sum, behavioral as well as neuroscientific studies in adults have provided evidence that the rapid processing of facial expressions is primarily driven by LSF information and that this might be driven by a rapid subcortical face-processing route that is preferentially tuned to LSF information. This quick and dirty route is thought to bypass the slower cortical route and is thought to modulate directly activity of specialized cortical areas in response to faces.

Little is known about the role of LSF and HSF in the perception of facial expressions in children. As described previously, there is converging evidence from studies in adults for a subcortical face-processing route that is rapid, operates on LSFs, and modulates cortical processing. The development of this pathway has not been studied, but Johnson (2005) suggested that newborn face processing and face preferences might primarily rely on this subcortical route or a precursor of it. This suggestion is based on evidence that face processing in newborns is primarily driven by subcortical pathways or brain structures as the visual and other cortical areas are still relatively immature.

In addition, the infant's limited visual capacities play a role in face processing in the 1st year of life. The vision of a newborn is solely based on LSF information (Acerra, Burnod, \& de Schonen, 2002; Morison \& Slater, 1985; Slater \& Sykes, 1977). This is caused by immaturity of the visual system at several levels, such as lower photoreceptor density and shorter segment length at the retina level, relatively less developed parvocellular neurons (compared to magno-) at the lateral geniculate nucleus level and lower synaptic density and lar- 
ger cortical receptive field size in the visual cortex (for reviews, see Ellemberg, Lewis, Liu, \& Maurer, 1999; Hammarrenger et al., 2003). In agreement with this, a recent study by de Heering et al. (2008) found that face recognition in newborns is primarily steered by very low $\mathrm{SF}(<0.5 \mathrm{cpd})$ information.

However, during infancy and early childhood, the visual system develops and other cortical areas also mature. Vision rapidly increases and, by the age of 3-4 years, sensitivity to HSF as measured by the contrast sensitivity function reaches maturity (e.g., Adams \& Courage, 2002). The contrast sensitivity function measures the amount of contrast that is needed to detect a stimulus with a certain SF. Until now, no studies have addressed whether the type of information, HSF or LSF, that is important for rapid facial expression processing changes during development as children become able to perceive a larger range of spatial frequencies.

There is only one behavioral study (Deruelle \& Fagot, 2005) that reported that 5- to 8-year-old children, like adults (Schyns \& Oliva, 1999; Vuilleumier et al., 2003), rely on HSF information when explicitly processing emotional expressions from faces (deciding whether a face is smiling or not). There is, however, no information on whether the rapid processing of facial expressions in children is, as in adults, based on LSF information.

A better understanding of normal development of facial expression processing is important as facial expressions play an important role in the social-emotional development of children. In this study, we investigate the role of SF in facial expression processing in children 3-8 years old using ERPs. We primarily investigate the early stages of face processing in the visual areas of the brain, where interactions between SF and emotion have been found to occur in previous studies (Pourtois et al., 2005; Vlamings et al., 2009). Two visual peaks were studied: P1 and N170. The P1 is a positivity peak that occurs $100 \mathrm{~ms}$ after stimulus onset (SO). It is a fast exogenous response that reflects striate as well as extrastriate visual processing (e.g., Rossion et al., 1999). The N170 (negativity at $170 \mathrm{~ms}$ after SO) originates from a network of regions, probably including the fusiform gyrus, inferior occipital cortex, superior temporal sulcus and the inferior, middle and superior temporal gyri (Henson et al., 2003). The N170 is the earliest "face-specific" ERP component as its amplitude has been found to be consistently enhanced in response to faces in comparison to multiple other nonface, object categories (see for review Jacques \& Rossion, 2004). A larger or faster P1 has been found for fearful compared to neutral expressions in adults (Eimer \& Holmes, 2002; Pourtois, Grandjean, Sander, \& Vuilleumier, 2004; Pourtois et al., 2005; Williams et al., 2004) as well as in infants (starting from 7 months of age) and children (Batty \& Taylor, 2006; Dawson, Webb, Carver, Panagiotides, \& McPartland, 2004; Nelson \& de Haan, 1996). Other studies report effects of emotional expressions on the N170 peak. Typically, larger N170 amplitudes are seen in response to (negative) emotional expressions than to neutral or positive expressions in adults (Batty \& Taylor, 2003, 2006; Blau, Maurer, Tottenham, \& McCandliss, 2007; Campanella, Quinet, Bruyer, Crommelinck, \& Guerit, 2002; Dawson et al., 2004; de Haan, Nelson, Gunnar, \& Tout, 1998; Stekelenburg \& de Gelder, 2004). In children, effects of (negative) emotional expression on the N170 have been reported in 3- to 4-year-olds (Dawson et al., 2004) and 5-year-olds (de Haan et al., 1998). However, a recent study by Batty and Taylor (2006) investigating facial expression processing from early childhood to adolescence indicated that early effects of negative emotion do not occur at the face-specific N170 until the age of 14-15. The latencies of these early effects at both P1 and N170 are usually somewhat delayed in infants and children compared to adults. Although the P1 and N170 results are not entirely consistent across developmental studies, the above-mentioned ERP studies underline the rapid $(<200 \mathrm{~ms})$ processing of emotional expressions in visual areas in both adults and children.

This study investigated effects of SF manipulations on the early processing of fearful facial expressions in the visual cortex in groups of 3- to 4year-old, 5- to 6-year-old, and 7- to 8-year-old children using the event-related potential technique. During a passive viewing task, we examined whether the effects of emotion expression at early visual information processing stages (P1 and N170) are primarily mediated by global LSF cues, as in adults, or by detailed HSF information. Through administration of an additional active behavioral task in which participants were required to categorize rapidly negative (fearful) or neutral face expressions, we aimed to explore the development of the role of spatial frequency on emotion recognition at the behavioral level. That is, we tested whether a LSF or HSF advantage for the processing of emotion would be reflected in reaction times. This behavioral task was only administered to the 5- to 6-year-old and 7- to 8-year-old children. 


\section{Method}

\section{Participants}

This study included 20 children (11 female, 9 male) between 3 and 4 years (mean age $=3.10$ years), 25 children (12 female, 13 male) between 5 and 6 years (mean age $=6.1$ years), and 25 children (12 female, 13 male) between 7 and 8 years (mean age $=7.8$ years) old. The children were recruited at an elementary school in Kerkrade (Netherlands). The 3- to 4-year-old group originally consisted of 27 participants, but 7 children dropped out due to ocular or muscular artefacts or an insufficient number of trials in which they looked at the screen.

To ensure that all children performed in the normal cognitive range (IQ > 90) for their age, children completed an IQ test. All 3- to 4-year-old children successfully completed the SON-R $2 \frac{1}{2}-7$ (Tellegen, Winkel, Wijnberg-Williams, \& Laros, 1998), and the 5- to 6-year-old and 7- to 8-year-old children performed two subtests of the WISC-III (Wechsler, 1991): the block design and vocabulary tests. The estimated total IQ score derived from these subtests has a mean reliability of .94 and a mean validity of .91 compared to the complete WISC-III (Spreen \& Strauss, 1998). (See Table 1 for mean total IQ scores for each age group.) No children were excluded based on IQ. Additionally, to check for behavioral problems, parents completed the Child Behavior Checklist (CBCL; Achenbach, 1991). The CBCL is an instrument used for the detection of behavioral problems in children. In the 7- to 8-year-olds, 3 children (of 28) were excluded before experimental testing took place because they scored in the clinical range (> 63) on the Internalizing (I), Externalizing (E), and Total Problem subscales of the CBCL (Achenbach, 1991). Participants had no neurological history and had normal or corrected to normal vision as verified by their parents. In the Netherlands, all children get a standard visual checkup at the age of 3 or 4 years. All parents gave written informed consent for their child's participation in the study. A local ethical committee of the Faculty

Table 1

Mean Full-Scale IQ Scores (SD in Parentheses) for the Three Age Groups

\begin{tabular}{lcr}
\hline & Full scale IQ & Range \\
\hline 3-4 years & $123.0(9.3)$ & $105-144$ \\
5-6 years & $114.6(10.2)$ & $90-131$ \\
7-8 years & $108.9(9.9)$ & $90-135$ \\
\hline
\end{tabular}

Note. Standard deviations are given in parentheses. of Psychology at Maastricht University, Netherlands, approved the experimental procedure.

\section{Stimuli and Task Procedure}

Face stimuli consisted of 16 grayscale images (8 males, 8 females), half of which depicted a neutral expression, while the other half depicted a fearful expression. Fearful and neutral expressions were from different individuals. The photographs were taken from the NimStim Face Set (http://www. macbrain.org/resources.htm; Tottenham, Borscheid, Ellertsen, Marcus, \& Nelson, 2002) and have been shown to evoke emotional effects at the level of the N170 in adults (Blau et al., 2007). Face images included European American and African American models. Fearful and neutral faces were equally balanced across race. Face pictures were trimmed to remove external features (neck and hairline). All pictures were fitted in a gray frame of $500 \times 700$ pixels. Each face subtended $6.3^{\circ}$ of visual angle at a distance of $113 \mathrm{~cm}$. The HSF images were created by filtering the original photographs using a high-pass cutoff of $\geq 6 \mathrm{cpd}$ of visual angle (see Figure 1). The LSF images were created using a low-pass filter of $\leq 2 \mathrm{cpd}$ of visual angle. Filtering was performed in Matlab (The Mathworks, Natick, MA) using a set of Gaussian filters.

The task consisted of four blocks, each containing 73 trials. Within each block, 64 faces and nine animation figures were presented on a gray background in randomized order. All faces were presented for $500 \mathrm{~ms}$ with an interstimulus interval of 1600-1800 ms. Participants were instructed to maintain fixation and to attend to all pictures. They had to press a response button as soon as they saw an animation figure on the screen and refrain from responding to all other images. This task was used to maintain the participant's attention during stimulus presentation. Short breaks were given between blocks. A video camera situated next to the screen recorded the child's gaze behavior. For 3- to 4-yearolds, looking behavior was coded offline, whereas it was monitored online for the 5- to 6-year-olds and 7- to 8-year-olds.

After the electroencephalogram (EEG) measurement, 5- to 6-year-old and 7- to 8-year-old children performed an additional reaction time task in which they had to decide as quickly and accurately as possible whether faces looked fearful or "usual" (neutral). Presentation time and interstimulus intervals were kept the same as in the initial ERP task. Participants started with a practice block that contained three phases. In the first phase, participants 


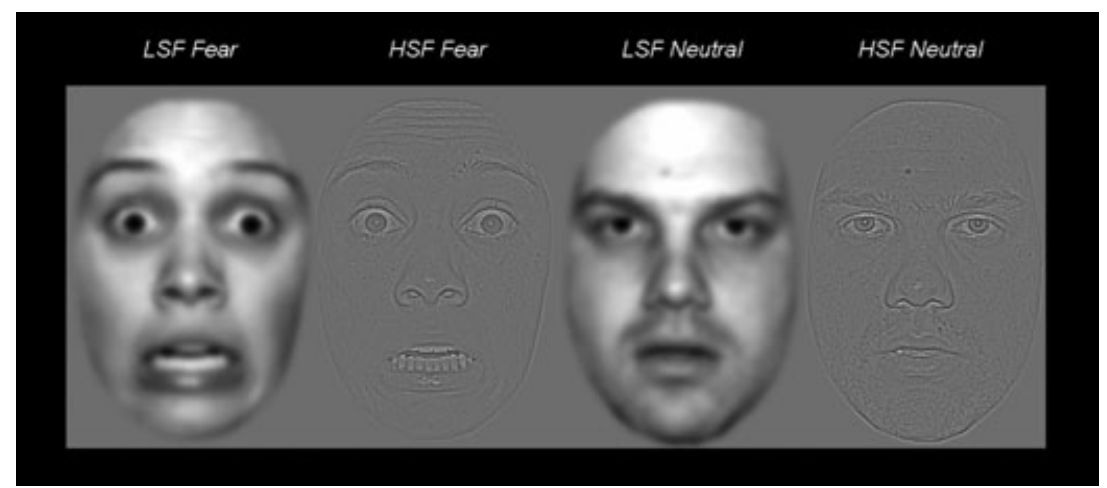

Figure 1. Examples of fearful and neutral low spatial frequency (LSF; $<2 \mathrm{cpd}$ ) and high spatial frequency (HSF; $>6$ cpd) face stimuli.

were presented with a face of a lion with a fearful expression and were asked: "How does the lion look?" Incorrect answers were corrected by the experimenter. Thereafter participants were presented with a face of a lion that looked neutral and were asked: "How does the lion look?" Incorrect answers were again corrected by the experimenter. In the second phase, participants were presented with a block of 32 trials in which they had to decide whether the face of the lion looked "usual" or "fearful" by pressing a left- or right-hand button. The duration of stimulus presentation was locked to the button response. In the third phase, participants had to perform the same task as in Phase 2, but now with experimental task parameters: a fixed stimulus duration of $500 \mathrm{~ms}$ with an interstimulus interval of 1600-1900 ms. After the last phase, participants were told that they now had to perform a similar task that contained faces of humans instead of lion faces. Half of the stimuli (neutral) required a left button press whereas the other half (fearful) required a right button press. Left and right button presses were counterbalanced across participants. Right-left assignment was the same in the training and test conditions.

The task contained the same number of stimuli (256) as the initial task ERP but was divided into eight blocks. Furthermore, no animation figures were presented between trials.

\section{ERP Recordings}

Event-related brain potentials were recorded via a QuickCap (Compumedics, Victoria, Australia) containing 60 electrodes, of which 37 electrodes were used. The electrodes were placed according to the 10-20 system with intermediate positions (see Figure 2) and comprised Fp1/2, Fz, F3/4, F7/8, FC1/2, FC5/6, FT9/10, Cz, C3/4, T7/8, CP1/2,

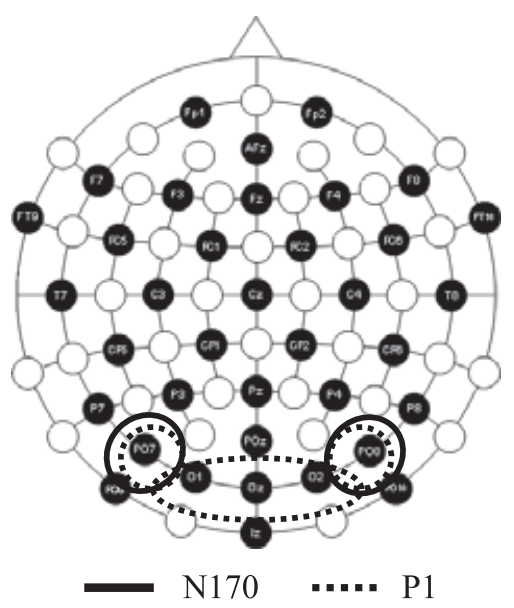

Figure 2. Scalp locations of the 36 electrodes.

Note. Mean amplitude and latency of the P1 were measured at pooled electrode sites: OZ/O1/O2/PO7/PO8. Mean amplitude and latency of the N170 were measured at occipito-temporal electrodes PO7/PO8.

CP5/6, Pz, P3/4, P7/8, POz, PO7/8, Oz, O1/2, Iz, and $\mathrm{PO} 9 / 10$ plus a ground electrode at AFz.

Four additional electrodes placed above and below the left orbit and on the outer canthus of each eye were used to monitor vertical and horizontal eye movements. All electrodes were referenced to the left mastoid online and A2 was measured as an active electrode. Impedances were kept below $20 \mathrm{k} \Omega$. A continuous EEG was recorded with a $500 \mathrm{~Hz}$ sampling rate and a band-pass filter of 0.01-200 Hz. The EEG data were analyzed offline using "Vision Analyser" software (Brain Products, Munich, Germany). The EEG data were epoched offline into 1500-ms periods, starting $200 \mathrm{~ms}$ prior to and ending $1300 \mathrm{~ms}$ after stimulus onset. Thereafter, the epochs were filtered $(0.1-30 \mathrm{~Hz})$, and artefacts from horizontal eye movements and blinks were reduced with the algorithm of Gratton, Coles, 
(a)

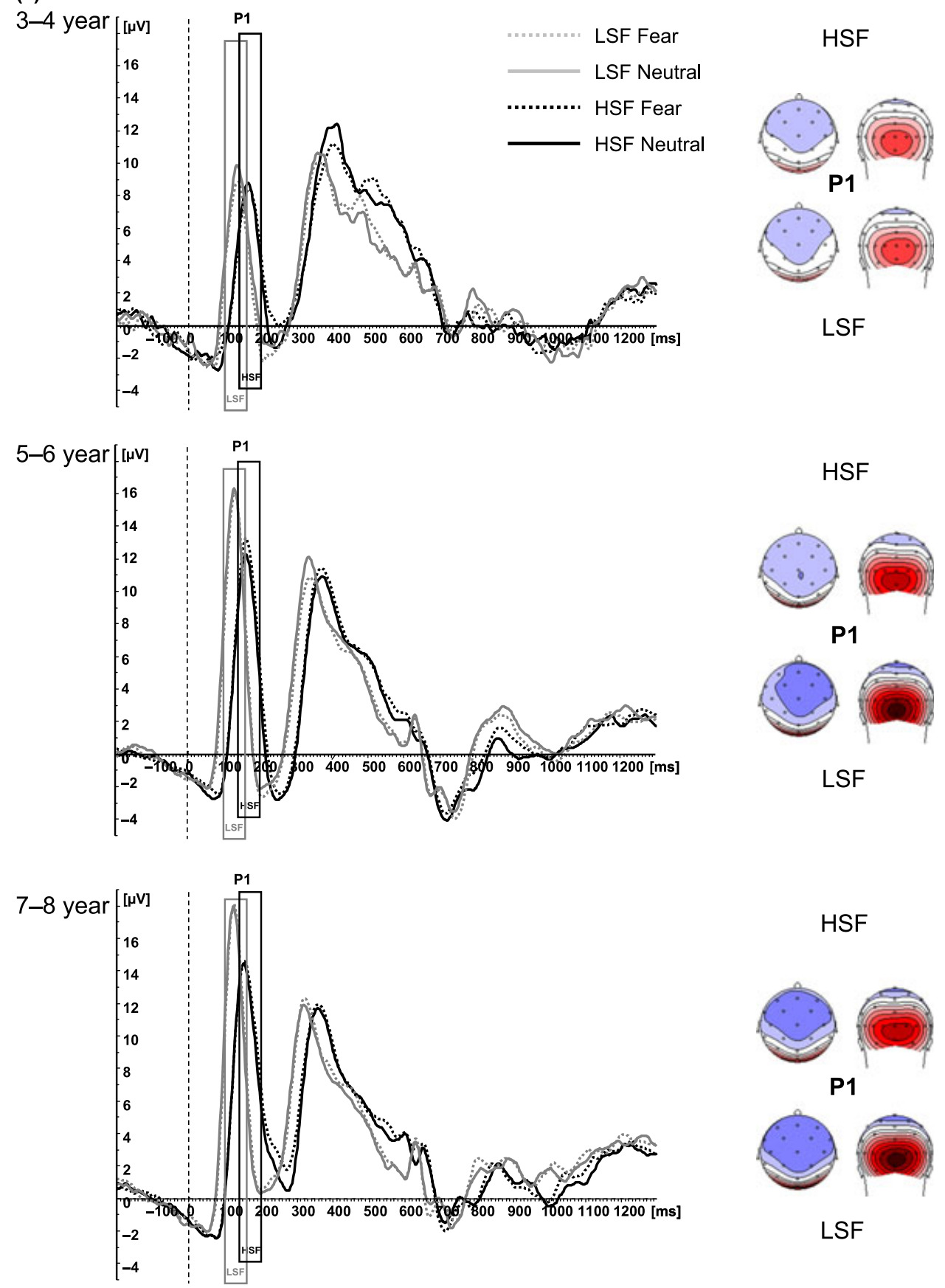

Figure 3. (a) Grand-average waveforms for 3- to 4-year-old, 5- to 6-year-old, and 7- to 8-year-old children at pooled electrodes (Oz/O1/O2/PO7/PO8), from which the P1 was extracted. In addition, the topographical distribution of the P1 is shown.

Note. The gray (low spatial frequency [LSF]) and black (high spatial frequency [HSF]) windows indicate the time windows over which P1 amplitude averages were calculated and P1 peak latency was extracted for statistical analysis. Note that because there is a difference between the way in which the grand-average waveforms (displayed in a and b) and the data used for statistical analysis are calculated (mean amplitudes across a predefined window; see Figure 4), the values in the current graphs may differ from the values used for statistical analysis (displayed in Figure 4).

(b) Grand-average waveforms for 3- to 4-year-old, 5- to 6-year-old, and 7- to 8-year-old children at electrodes PO7 and PO8, from which the N170 was extracted. In addition, topographical distributions of the N170 for HSF and LSF stimuli are shown.

Note. The gray (LSF) and black (HSF) windows indicate the time windows over which N170 amplitude averages were calculated and N170 peak latency was extracted for statistical analysis. 
(b)

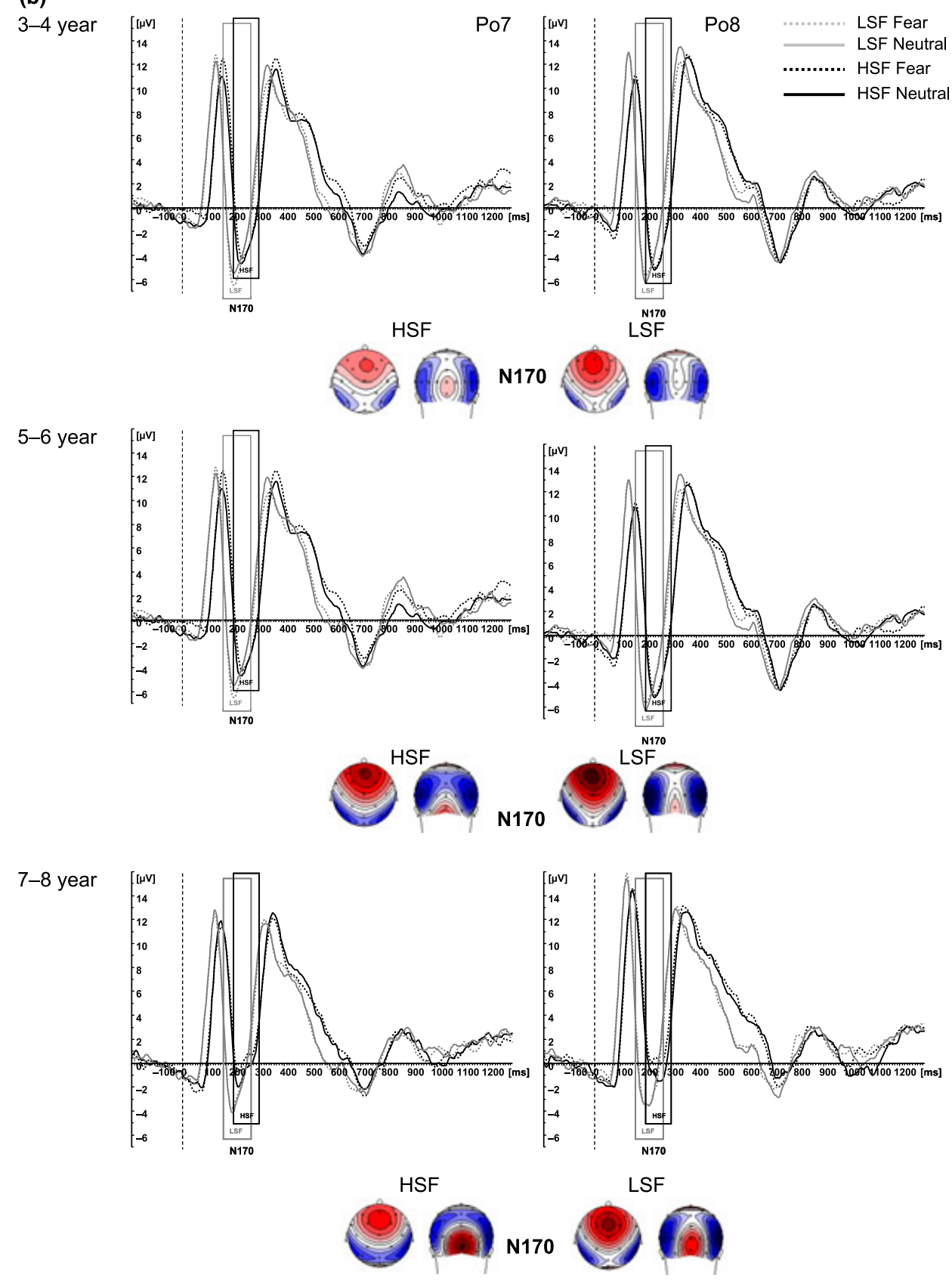

Figure 3. (Continued).

and Donchin (1983). After baseline correction (-200 to 0$)$, trials that contained EEG artefacts $( \pm 75 \mu \mathrm{V})$ were rejected from the data set. Furthermore, trials during which the child was not looking at the screen were discarded. Separate ERP averages were computed for all participants for the four stimulus conditions (SF: HSF, LSF) $\times($ emotion: fear, neutral). Finally, the data were rereferenced to an average reference.
According to Cacioppo, Tassinary, and Berntson (2000), a minimum of 20 electrodes are sufficient for average references calculation.

\section{Data Analysis}

Based on topographies (spherical spline calculation) and peak maxima (see Figures $3 a$ and $3 b$ ), regions or electrodes of interest were defined for 
Table 2

Time Windows and Electrodes for Mean Amplitude and Latency Extraction for P1 and N170

\begin{tabular}{lccc}
\hline ERP peak & LSF & HSF & Electrodes \\
\hline P1 & $100-160$ & $140-200$ & PO7, PO8, Oz, O1, O2 \\
N170 & $170-270$ & $200-300$ & PO7, PO8 \\
\hline
\end{tabular}

Note. $\mathrm{ERP}=$ event-related brain potential; $\mathrm{LSF}=$ low spatial frequency; HSF = high spatial frequency.

both the P1 and N170 components (see Figure 2). Time windows for the components of interest (see Table 2) were chosen through visual inspection of the grand-average waveforms in all groups (see Figures $3 a$ and $3 b$ ), which show a clear latency shift between LSF and HSF ERPs and show emotion effects (amplitude difference between fear and neutral) at the chosen time points. To measure P1 and N170 amplitudes, mean area amplitudes across a predefined time window (see Table 2) were used instead of peak amplitudes for two reasons. First, emotional effects were present across a broader time window and did not occur only at the peak (see Figures $3 \mathrm{a}$ and $3 \mathrm{~b}$ ). Second, mean areas are less sensitive to high-frequency noise then peak amplitudes (Luck, 2005).

The three groups differed in mean number of total trials included in the analyses, $F(2,67)=57.26$, $p<.001$, with fewer trials for the 3- to 4-year-olds (high neutral $[\mathrm{HN}]=41, S D=11$, range $=25-64$; high fear $[\mathrm{HF}]=42, S D=10$, range $=27-62$; low neutral $[\mathrm{LN}]=43, S D=9$, range $=28-63$; low fear [LF]: $43, S D=10$, range $=27-64)$ compared to the 5- to 6-year-olds $(\mathrm{HN}=59, S D=8$, range $=34-64$; $\mathrm{HF}=59, S D=7$, range $=38-64 ; \mathrm{LN}=59, S D=8$, range $=33-64 ; \mathrm{LF}=59, S D=8$, range $=33-64)$ and 7- to 8-year-olds $(\mathrm{HN}=61, S D=5$, range $=40-64$; $\mathrm{HF}=60, S D=5$, range $=43-64 ; \mathrm{LN}=60, S D=5$, range $=41-64 ; \mathrm{LF}=61, S D=5$, range $=48-64)$. Mean areas do not become biased when the noise level increases due to different trial numbers. Consequently, it is legitimate to compare mean amplitude measurements from waveforms based on different numbers of trials, whereas this is not legitimate for peak amplitude measurements (Luck, 2005). However, note that the lowest number of total trials included in the analysis $(n=25)$ can still be considered high. The mean amplitude of the P1 was extracted from a pooled set of occipito-temporal electrodes: PO7/PO8/Oz/O1/O2 (see Figure 2). The amplitude data were subjected to a 2 (SF: HSF, LSF) $\times 2$ (emotion: fear, neutral) $\times 3$ (group: 3 - to 4year-olds, 5- to 6-year-olds, 7- to 8-year-olds) analysis of variance (ANOVA). The mean amplitude of the N170 was extracted from electrodes PO7 and PO8 (see Figure 2). N170 data were subjected to a 2 (SF: HSF, LSF) $\times 2$ (emotion: fear, neutral) $\times 2$ (hemisphere: PO7, PO8) $\times 3$ (group: 3- to 4-yearolds, 5- to 6-year-olds, 7- to 8-year-olds) ANOVA. Because the topographical distribution of the P1 did not show any laterality effects, we did not include this factor in the analysis. The location from which the different components were extracted is consistent with several ERP studies in children (see, e.g., Batty \& Taylor, 2006; Dawson et al., 2004).

Because the grand averages (see Figures $3 a$ and $3 \mathrm{~b}$ ) showed clear effects of SF on peak latency at the P1 and N170, we also analyzed peak latency for HSF and LSF. Although peak latencies, like peak amplitudes, are prone to high-frequency noise and have other shortcomings, there are not many good alternatives and so they are often the best measure (Luck, 2005). Based on the suggestions of Luck (2005), we took the following precautions: (a) We filtered out the high-frequency noise in the waveforms by filtering the preprocessed data with an additional $10-\mathrm{Hz}$ low-pass filter (note, however, that using a $30-\mathrm{Hz}$ low-pass filter, the latency results were replicated). (b) We used a peak detection algorithm that looked for local peak maxima rather than an absolute peak measure. When searching for local maxima, the automatic peak detection algorithm looks for extreme values within a given interval and considers the edge values only if this search fails. The difference between a local and an absolute maximum is that, in searching for an absolute maximum, the edge points of the intervals are found as peaks if the value there is greater (or less) than all values within the interval. (c) We only analyzed the effect of SF (which was clearly present in the data; see Figures $3 a$ and $3 b$ ) in the different age groups, which resulted in a relatively high number of trials per condition (maximum $=128$ ). Previous studies in adults have indicated that interactions between SF and emotion affect P1 and N170 amplitude only (Pourtois et al., 2005; Vlamings et al., 2009). P1 latency was extracted from a pooled set of occipito-temporal electrodes: PO7/PO8/Oz/O1/O2 (see Figure 2). P1 latency was subjected to a 2 (SF: HSF, LSF) $\times 3$ (group: 3- to 4-year-olds, 5- to 6-year-olds, 7- to 8year-olds) ANOVA. N170 latency was derived from electrodes PO7 and PO8 (see Figure 2) and these data were subjected to a 2 (SF: HSF, LSF) $\times 2$ (hemisphere: PO7, PO8) $\times 3$ (group: 3- to 4-yearolds, 5- to 6-year-olds, 7- to 8-year-olds) ANOVA.

Reaction times (only reaction times between 150 and $2100 \mathrm{~ms}$ after stimulus onset were included in 
the analysis) and percentage hits from the separate categorization task were subjected to a 2 (SF: HSF, LSF) $\times 2$ (emotion: fear, neutral) $\times 2$ (group: 5- to 6-year-olds, 7- to 8-year-olds) ANOVA. Four participants (three 5- to 6-year-olds and one 7- to 8-yearold) were excluded (significant outliers) from the analysis because they had too many misses.

When statistically significant first-, second-, or third-order interactions were found, these were further tested by looking at partial interactions in a fixed order (SF, emotion, hemisphere, and group). The higher order interactions had to be significant before lower order interactions were considered. When testing of significant interactions did not lead to significant results, these are not mentioned in the study.

Finally, for the 5- to 6-year-olds and 7- to 8-yearolds, correlation analyses were performed between behavioral measures (reaction times and percentage correct) and P1 and N170 amplitude and latency data in the different conditions.

\section{Results}

Grand averages and topographical distributions of the P1 and N170 are depicted in Figures 3a and 3b. The mean values and standard errors of mean amplitude and latency measures of the P1 and N170 used for statistical analysis are depicted in Figures 4 and 5.

\section{P1 Amplitude}

The overall four-way ANOVA revealed an interaction between SF and emotion, $F(1,67)=5.42$, $p<.05, \eta_{p}^{2}=.08$. Pairwise comparisons indicated significantly higher P1 amplitudes for fearful compared to neutral faces presented at HSF, $t(69)=2.61$, $p<.05, \eta_{p}^{2}=.09$ (see Figures 3a and 4), whereas the difference between neutral and fearful faces was not significant for LSF faces. Furthermore a main effect of group was found irrespective of $\mathrm{SF}, F(2,67)=$ 10.22, $p<.001, \eta_{p}^{2}=.23$, showing that P1 amplitudes of 3- to 4-year-old children were larger than those in 5- to 6-year-old children, $t(43)=-3.65$, $p<.01$, Cohen's $d=-1.39$, and 7- to 8-year-old, $t(43)=-4.73, p<.001$, Cohen's $d=-1.14$ (see Figures $3 a$ and 5). Other main effects were not found.

\section{P1 Latency}

The analysis of peak latency of $\mathrm{P} 1$ only revealed a significant main effect of $\mathrm{SF}, F(1,67)=549.59$, $p<.001, \eta_{p}^{2}=.89$, with HSF faces showing longer P1 latencies than LSF faces (see Figures 3a and 5).

\section{N170 Amplitude}

The overall four-way ANOVA revealed a significant interaction between SF and emotion, $F(1,67)=$ 9.20, $p<.01, \eta_{p}^{2}=.10$. There were no main effects. As for P1, pairwise comparisons indicated a significant effect of emotion for HSF faces only. For the N170, however, neutral HSF faces elicited significantly higher amplitudes than HSF fearful faces, $t(69)=-3.67, p<.001, \eta_{p}^{2}=.11$, whereas there was no effect of emotion for LSF faces (see Figures $3 b$ and 4).

\section{N170 Latency}

For N170 peak latency, we only found a significant SF $\times$ Group interaction, $F(2,67)=4.42, p<.05$, $\eta_{p}^{2}=.12$ and no main effects. The SF effect was significant in each of the age groups, with LSF faces showing shorter peak latencies than HSF faces: 3 - to 4-year-olds, $t(19)=-5.04, p<.001, \eta^{2} \mathrm{p}=$ .57 ; 5 - to 6-year-olds, $t(24)=-13.09, p<.001, \eta_{p}^{2}=$ $.88 ; \quad 7$ - to 8-year-olds, $t(24)=-18.34, p<.001$, $\eta_{p}^{2}=.93$ (see Figures $3 b$ and 5). Further analysis revealed a significant effect of group for LSF faces only, $F(2,67)=3.68, p<.05$. Three- and 4-year-old children had longer N170 latencies than 7- to 8year-old children, $t(43)=2.54, p<.05, \eta_{p}^{2}=.10$ (see Figures $3 b$ and 5), when presented with an LSF face, whereas there was no difference between the 3- to 4-year-olds and 5- to 6-year-olds. Post hoc correlation analyses indicated a significant negative correlation between age in months (including all age groups) and latency for LSF faces $r=-.27$, $p<.05$. This effect was absent for HSF faces.

\section{Percentage Hits-Categorization Task}

Analysis of the percentage hits recorded in the categorization task in the 5- to 6-year-olds and 7- to 8 -year-olds indicated a marginally significant Group $\times$ Emotion interaction, $F(1,44)=3.99, p=$ $.052, \eta_{p}^{2}=.08 ; 7$ - to 8-year-olds performed slightly better on neutral compared to fearful faces, $t(23)=-3.02, p<.01, \eta_{p}^{2}=.28$, but there was no stimulus difference for 5- to 6-year-olds. When testing group differences for neutral and fearful stimuli, 5- to 6-year-olds had fewer hits in the neutral condition compared to 7- to 8-year-olds, $t(44)=-2.58$, $p<.05, \eta_{p}^{2}=.13$. There was a significant positive correlation between age in months and percentage 
P1
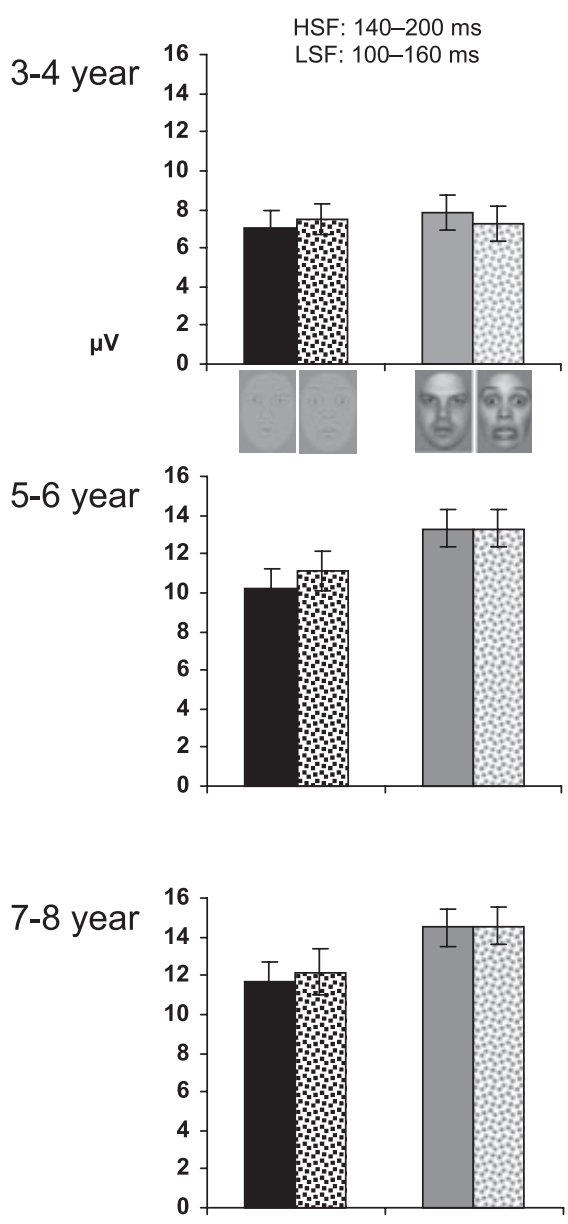

All

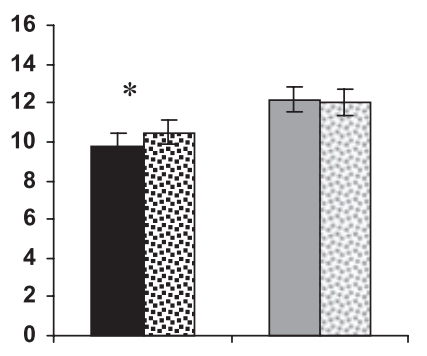

LSF Fear

LSF Neutral

HSF Fear HSF Neutral
N170

HSF: $200-300 \mathrm{~ms}$ LSF: $170-270 \mathrm{~ms}$
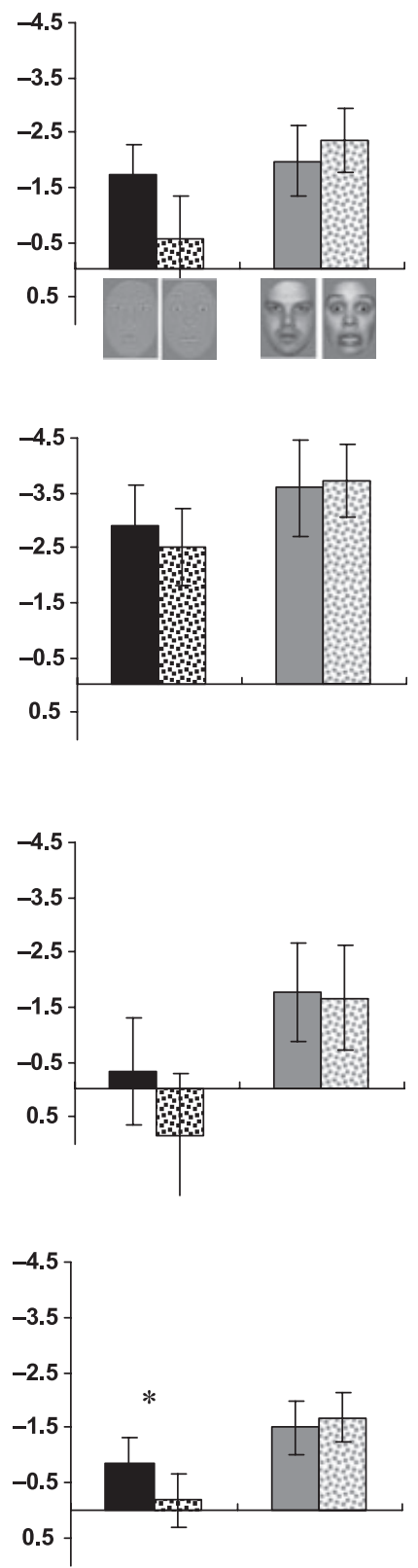

Figure 4. Bar graphs of the mean amplitudes $(+S E)$ of the P1 and N170 in all stimulus conditions (high spatial frequency [HSF] fear, HSF neutral, low spatial frequency [LSF] fear, LSF neutral) are shown separately for each age group.

Note. Note that because there is a difference in the way in which the grand averages (displayed in Figures $3 a$ and $3 b$ ) and the data used for statistical analysis, shown in the bar graphs in this figure, are calculated, the values in the current graphs may differ from the values displayed in Figures $3 \mathrm{a}$ and $3 \mathrm{~b}$. In the top row, the windows over which the amplitude averages were calculated are reported for P1 and N170. 

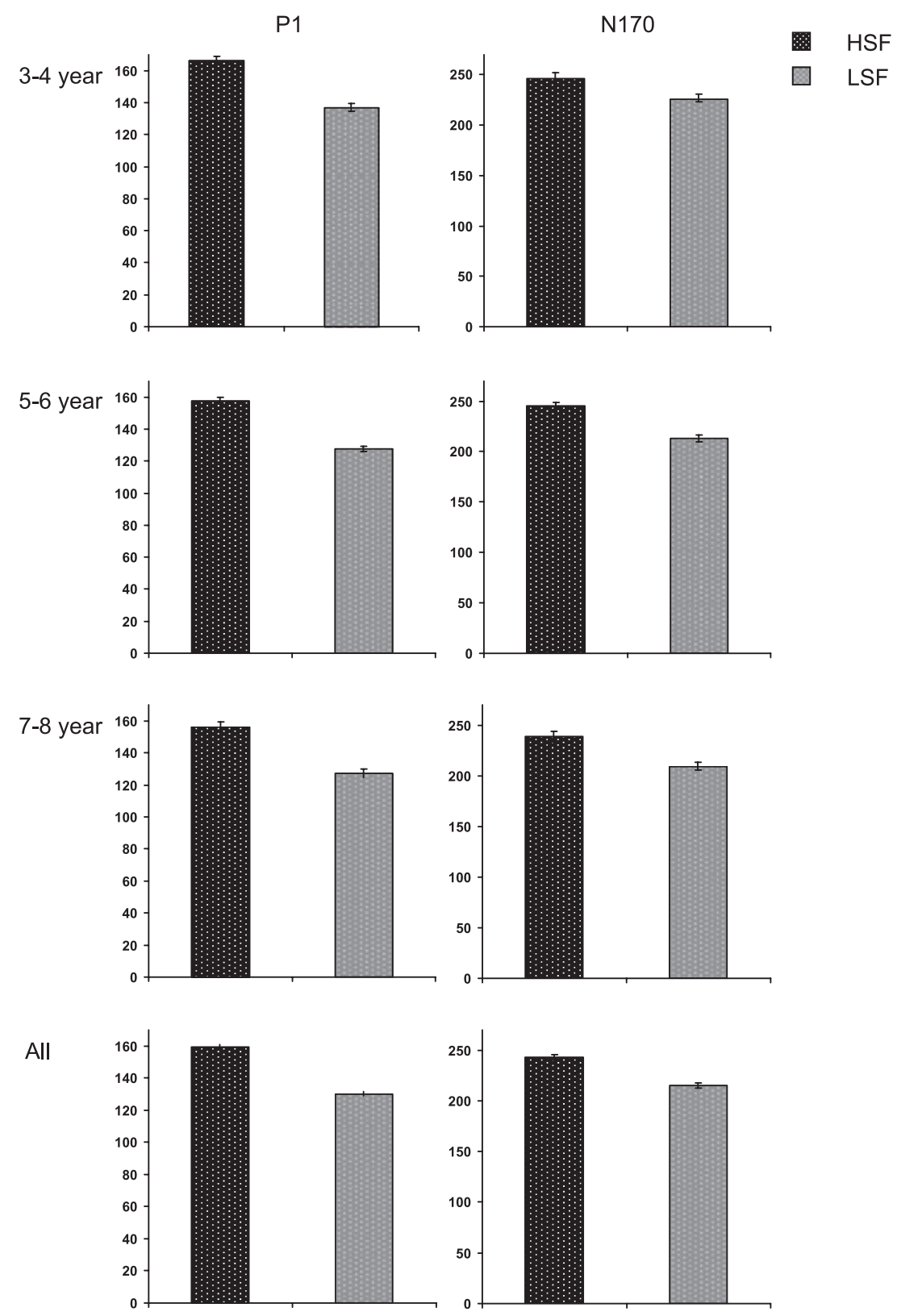

Figure 5. Bar graphs of the mean latencies $(+S E)$ of the P1 and N170 in all stimulus conditions (high spatial frequency [HSF] and low spatial frequency [LSF]) are shown separately for each age group.

of correct trials in the neutral condition, $r=.35$, $p<.05$, but not in the fearful condition.

\section{Reaction Times-Categorization Task}

Analysis of the reaction times revealed a marginally significant effect of emotion, $F(1,44)=3.96$, $p=.053, \eta_{p}^{2}=.08$, indicating faster reaction times to recognize fearful than neutral faces (see Table 3). In addition, we found a main effect of SF, $F(1$,
44) $=39.69, p<.001, \eta_{p}^{2}=.74$. Participants were faster, overall, in categorizing LSF faces than HSF faces (see Table 3).

Correlation Between Behavioral Performance and ERP Measures

In none of the conditions were significant correlations between reaction times or percentage hits and P1/N170 latency or amplitude found. 
Table 3

Mean Reaction Times (RT) and Percentage Hits for All Stimulus Conditions Averaged Across 5- to 6-Year-Old and 7-to 8-Year-Old Children

\begin{tabular}{|c|c|c|c|c|}
\hline & \multicolumn{2}{|c|}{ LSF } & \multicolumn{2}{|c|}{ HSF } \\
\hline & Neutral & Fear & Neutral & Fear \\
\hline \multicolumn{5}{|c|}{ Hit RT (years) } \\
\hline 5-6 & $1001(45)$ & $988(44)$ & $1030(43)$ & 1019 (44) \\
\hline $7-8$ & 986 (29) & $961(33)$ & $1026(31)$ & $1002(31)$ \\
\hline \multicolumn{5}{|c|}{ Hit percentage (years) } \\
\hline 5-6 & $70(5)$ & $75(3)$ & $69(4)$ & $72(4)$ \\
\hline $7-8$ & $83(3)$ & $81(3)$ & $81(3)$ & $75(3)$ \\
\hline
\end{tabular}

Note. Standard errors are given in parentheses. LSF = low spatial frequency; HSF = high spatial frequency.

\section{Discussion}

The aim of this study was to investigate the effect of manipulation of the spatial frequency content (LSF and HSF) of face stimuli on the rapid processing of negative (fearful) and neutral facial expressions in the visual cortex of 3- to 8-year-old children. Recent studies have revealed that, in adults, early effects of facial emotion content $(<200 \mathrm{~ms})$ on ERP components above the visual cortex (P1 and N170), are primarily mediated by LSF information (Pourtois et al., 2005; Vlamings et al., 2009).

In contrast, in this study we found that the early effects of emotion expression detection at the P1 were driven primarily by more detailed HSF information in all children (such as contours of the eyes, eyebrows, mouth, and so on). This was shown by higher P1 amplitudes for fearful compared to neutral faces for HSF images only. Similar enhanced P1 amplitudes in response to broadband fearful face stimuli (containing all frequencies) are typically interpreted as reflecting involuntary capture of attention by fear (e.g., Pourtois et al., 2004, 2005). Whereas this Emotion $\times$ SF interaction effect was found for all children, a group main effect indicated that P1 amplitude decreased with age, consistent with Batty and Taylor (2003, 2006). These authors suggested that this developmental effect reflects automatization of visual processing in general. However, main effects of group on ERP amplitude are difficult to interpret and might also reflect structural brain changes. To exclude the possibility that the P1 findings were influenced by unintended differences in low-level visual characteristics between neutral and fearful faces resulting from filtering, additional analyses were performed. These analyses indicated that the spatial frequency content of the two expression types did not differ sub- stantially, making it highly unlikely that such differences influenced the present results. Furthermore, the present results show that besides for P1, also for the face-specific N170, effects of emotional expression are driven by a different type of $\mathrm{SF}$ information compared to adults (Vlamings et al., 2009).

A possible explanation for this developmental effect must take into account findings that consistently show that infants just a few months old already have a "preference" for fearful faces, as shown by longer looking times (Kotsoni, de Haan, \& Johnson, 2001; Nelson \& Dolgin, 1985; Peltola, Leppänen, Mäki, \& Hietanen, 2009) and larger ERP responses to fearful than other faces (de Haan, Belsky, Reid, Volein, \& Johnson, 2004; Leppänen, Moulson, Vogel-Farley, \& Nelson, 2007; Nelson \& de Haan, 1996). This early preference for fear is most probably mediated by LSF cues since, due to immaturity of the visual system, 6- to 12-month-old infants have very little sensitivity to HSF (de Heering et al., 2008; Slater \& Sykes, 1977). Integrating this literature with the present data yields the following developmental pattern: During infancy, the early visual processing of fearful expressions is (most strongly) mediated by LSF cues, followed by a shift to HSF cues in childhood as is shown by the present ERP data, then returning to the use of LSF cues in adulthood (Pourtois et al., 2005; Vlamings et al., 2009).

The enhanced use of HSF cues for early visual processing of fear during childhood, as opposed to LSF cues in adults, might be linked to immaturity of the subcortical face-processing route (see the Introduction). This route makes use of LSF and is suggested to boost P1 amplitudes to fearful LSF faces through direct modulating feedback signals coming from the amygdala (Pourtois et al., 2005). In support of this hypothesis, Cunningham, Bhattacharyya, and Benes (2002) found that amygdalacortical connectivity continues to mature into adolescence, at least in the prefrontal areas. However, such an explanation would be difficult to reconcile with findings suggesting that the subcortical face-processing route is already functional in newborns and probably plays a crucial role in the bias for fearful expressions that is already present at this age (see for review Johnson, 2005; Morton \& Johnson, 1991). Finally, the conclusion that early LSFbased processing of fearful expressions in adults is mediated by a rapid subcortical processing route is, as yet, only derived from indirect evidence (see Pourtois et al., 2005; Vuilleumier et al., 2003). It is possible that this early, LSF-based, facial emotion 
processing in the visual cortex results from a rapid feedforward cortical projection within the visual system itself. Future studies, possibly using fMRI (or a combination of fMRI and EEG), should be aimed at further disentangling these possibilities.

An alternative explanation that takes into account both the maturation of the visual system and the influence of developmental differences in expertise with face processing might better fit the data. As the ability to resolve HSF only reaches maturity at 3-4 years (e.g., Adams \& Courage, 2002), children presumably might not be able to process relevant HSF emotional cues before that age. This is supported by findings showing that infants use mainly LSF cues for face processing (de Heering et al., 2008). At the age of 3-4 years, however, the ability to resolve HSF information reaches maturity, and HSF information might become most efficient for the rapid extraction of emotion, as found in this study at least up to 8 years. The developmental shift to the use of LSF cues again in adulthood, as seen in both P1 and N170, might in turn be related to increased expertise with facial expressions and faces in general.

Some evidence for such an expertise account comes from a study by Schyns and Oliva (1999), showing that adults more frequently used LSF information for face identification when they were familiarized with faces by training. A similar effect was found for object identification by Viggiano, Righi, and Galli (2006). In addition, several studies show stronger configural processing (i.e., a larger inversion effect) for face stimuli for which participants have expertise (see for review McCleery et al., 2008; Parr \& Heintz, 2008), and LSFs are known to play an important role in such configural face processing (Flevaris, Robertson, \& Bentin, 2008; Goffaux, Gauthier, \& Rossion, 2003; Goffaux, Hault, Michel, Vuong, \& Rossion, 2005).

Surprisingly, the HSF emotion effect in the 3-8year-old children at the N170 was opposite to that of the P1. The P1 data suggest increased processing of fearful HSF stimuli, while, at the N170, amplitudes were larger in response to neutral than fearful HSF stimuli. This might be due to ambiguity of neutral faces for young children. A recent study showed that before the age of 9 years, children often rate neutral faces as happy or sad (Durand, Gallay, Seigneuric, Robichon, \& Baudouin, 2007; see also Carlson, Felleman, \& Masters, 1983; Felleman, Barden, Carlson, Rosenberg, \& Masters, 1983; Reichenbach \& Masters, 1983). In this study, the oldest (7-8 years old) children also correctly categorized a higher percentage of neutral faces than 5- to 6-year- olds. Additionally, Thomas et al. (2001) demonstrated greater amygdala activity in response to neutral faces than fearful faces in children than adults (see also Tottenham, Hare, \& Casey, 2009). It was argued that this enhanced activity might signal increased effort invested in the decoding of the neutral face expression that is perceived as ambiguous by children. Such an explanation would be congruent with the fact that amplitudes to neutral faces were only enhanced for the N170 and not the P1 in this study. As opposed to the P1, which is assumed to be primarily sensitive to low-level visual processing or attentional manipulations, the N170 is thought to be especially involved in structural encoding of faces (Jacques \& Rossion, 2006; Nobre, Rao, \& Chelazzi, 2006; Taylor, 2002; Valdes-Sosa, Bobes, Rodriguez, \& Pinilla, 1998).

With respect to the latencies of the P1 and N170, we found faster latencies for processing of LSF compared to HSF stimuli, irrespective of facial expression, which is consistent with findings in adults for facial (Halit, de Haan, Schyns, \& Johnson, 2006; Hsiao, Hsieh, Lin, \& Chang, 2005; McCarthy, Puce, Belger, \& Allision, 1999) and nonfacial (Mihaylova, Stomonyakov, \& Vassilev, 1999; Musselwhite \& Jeffreys, 1985) stimuli. Similar effects were found with respect to reaction times in the current behavioral categorization task. The temporal precedence of LSF is consistent with findings that the neuronal pathways sensitive to LSF and HSF have dissociable time scales, with faster cortical arrival of information that is processed in the LSF-sensitive magnocellular pathway (see for review Laycock, Crewther, \& Crewther, 2007).

Importantly, the latency of the N170 decreased in the LSF condition with increasing age, whereas there were no significant age effects for processing of HSF faces. Faster N170 latencies with increasing age have previously been reported for face stimuli containing all SF frequencies (see for review Taylor, Batty, \& Itier, 2004). This study thus suggests that this decrease in N170 latency to unfiltered faces might be caused specifically by faster extraction of LSF information. In contrast to these developmental effects on N170 latency for LSF, no age effects were found with respect to P1 and N170 amplitude. That is, early effects of emotion at P1 and N170 amplitude were primarily driven by HSF, and this did not change with age. Integration of the latency and amplitude results suggests that although children seem to more rapidly extract LSF information for face processing with age, this information does not yet drive emotional processing during early faceprocessing stages. 
Finally, in a behavioral task, we investigated whether an LSF or HSF advantage for the processing of facial expressions would be reflected in reaction times to an active categorization task. Like adults (Vlamings et al., 2009), children decided more quickly that a face was fearful than that it was neutral, which is consistent with the finding that stimuli that signal threat receive preferential attention over neutral stimuli (see for review Holmes, Green, et al., 2005). The lack of an interaction between emotion and SF suggests that emotional expressions are recognized based on LSF as well as HSF information at later information processing stages (at response level). This is supported by data from another recent behavioral study that indicated that both HSF and LSF cues are used for emotion identification in typically developing children (one age group: 6-16 years; Deruelle, Rondan, Salle-Collemiche, Bastard-Rosset, \& Da Fonséca, 2007). We did not find evidence for an association between behavioral performance and ERP measures suggesting that in this study early and late stages of processing might not be directly linked.

In conclusion, the present data show that just as in adults, 3- to 8-year-old children show enhanced early visual brain responses (P1) to fearful compared to neutral faces. However, whereas prior work showed that this effect was mediated by LSF cues in adults and infants, present data showed that in children more detailed (HSF) face cues were used (such as eyes, mouth, and so on). The absence of an LSF bias for the processing of fear in 3- to 8year-olds might be explained by a combination of immaturity of the visual system to process HSF information and a lack of expertise with face processing that enables adults to rely on LSF information. Future studies with older age groups should establish when the processing of fear starts to be driven primarily by LSF information. Finally, our data suggest that a developmental latency decrease of the N170 could be linked to faster extraction of LSF cues with age. The present data might be important for research in neurodevelopmental disorders such as autism, for which specific deficits in the processing of LSF have been suggested (see for review Johnson, 2005; Laycock et al., 2007) and might lead to an investigation of how this LSF bias in autism is linked to the development of gaze behavior and face expertise. Finally, it should be noted that due to practical considerations, the present study only included one emotional expression (fear) and that the present effects thus cannot be generalized to general (negative) emotion processing, which should be the subject of a future study.

\section{References}

Acerra, F., Burnod, Y., \& de Schonen, S. (2002). Modelling aspects of face processing in early infancy. Developmental Science, 5, 98-117.

Achenbach, T. M. (1991). Manual for the Child Behavior Checklist 4-18. Burlington: Department of Psychiatry, University of Vermont.

Adams, J. A., \& Courage, M. L. (2002). Using a single test to measure human contrast sensitivity from early childhood to maturity. Vision Research, 42, 1205-1210.

Batty, M., \& Taylor, M. J. (2003). Early processing of the six basic facial emotional expressions. Cognitive Brain Research, 17, 613-620.

Batty, M., \& Taylor, M. J. (2006). The development of emotional face processing during childhood. Developmental Science, 9, 207-220.

Blau, V. C., Maurer, U., Tottenham, N., \& McCandliss, B. D. (2007). The face-specific N170 component is modulated by emotional facial expression. Behavioral and Brain Functions, 3, 7.

Cacioppo, J. T., Tassinary, L. G., \& Berntson, G. G. (2000). Handbook of psychophysiology. Cambridge, UK: Cambridge University Press.

Campanella, S., Quinet, P., Bruyer, R., Crommelinck, M., \& Guerit, J. M. (2002). Categorical perception of happiness and fear facial expressions: An ERP study. Journal of Cognitive Neuroscience, 15, 210-227.

Carlson, C. R., Felleman, E. S., \& Masters, J. C. (1983). Influence of children's emotional states on the recognition of emotion in peers and social motives to change another's emotional state. Motivation and Emotion, 7, 61-79.

Cunningham, M. G., Bhattacharyya, S., \& Benes, F. M. (2002). Amygdalo-cortical sprouting continues into early adulthood: Implications for the development of normal and abnormal function during adolescence. Journal of Comparative Neurology, 453, 115-130.

Dawson, G., Webb, S. J., Carver, L., Panagiotides, H., \& McPartland, J. (2004). Young children with autism show atypical brain responses to fearful versus neutral facial expressions of emotion. Developmental Science, 7, 340-359.

de Haan, M., Belsky, J., Reid, V., Volein, A., \& Johnson, M. H. (2004). Maternal personality and infants' neural and visual responsivity to facial expressions of emotion. Journal of Child Psychology and Psychiatry, 45, 12091218.

de Haan, M., Nelson, C. A., Gunnar, M. R., \& Tout, K. A. (1998). Hemispheric differences in brain activity related to the recognition of emotional expressions by 5-yearold children. Developmental Neuropsychology, 14, 495518.

de Heering, A., Turati, C., Rossion, B., Bulf, H., Goffaux, V., \& Simion, F. (2008). Newborns' face recognition is based on spatial frequencies below 0.5 cycles per degree. Cognition, 106, 444-454.

De Valois, R. L., \& De Valois, K. K. (1988). Spatial vision. New York: Oxford University Press. 
Deruelle, C., \& Fagot, J. (2005). Categorizing facial identities, emotions, and genders: Attention to high- and low-spatial frequencies by children and adults. Journal of Experimental Psychology, 90, 172-184.

Deruelle, C., Rondan, C., Salle-Collemiche, X., BastardRosset, D., \& Da Fonséca, D. (2007). Attention to lowand high spatial frrequencies in categorizing facial identities, emotions and gender in children with autism. Brain and Cognition, 66, 115-123.

Durand, K., Gallay, M., Seigneuric, A., Robichon, F., \& Baudouin, J. Y. (2007). The development of facial emotion recognition: The role of configural information. Journal of Experimental Child Psychology, 97, 14-27.

Eimer, M., \& Holmes, A. (2002). An ERP study on the time course of emotional face processing. Neuroreport, $25,427-431$.

Ellemberg, D., Lewis, T. L., Liu, C. H., \& Maurer, D. (1999). Development of spatial and temporal vision during childhood. Vision Research, 39, 2325-2333.

Enroth-Cugell, C., \& Robson, J. G. (1966). The contrast sensitivity of retinal ganglion cells of the cat. Journal of Physiology, 187, 517-552.

Felleman, E., Barden, R. C., Carlson, C. R., Rosenberg, L., \& Masters, J. C. (1983). Children's and adults' recognition of spontaneous and posed emotional expressions in young children. Developmenal Psychology, 19, 405-413.

Flevaris, A. V., Robertson, L. C., \& Bentin, S. (2008). Using spatial frequency scales for processing of face features and face configuration: An ERP analysis. Brain Research, 1194, 100-109.

Goffaux, V., Gauthier, I., \& Rossion, B. (2003). Spatial scale contribution to early visual differences between face and object processing. Brain Research, 16, 416-424.

Goffaux, V., Hault, B., Michel, C., Vuong, Q. C., \& Rossion, B. (2005). The respective role of low and high spatial frequencies is supporting configural and featural processing of faces. Perception, 34, 77-86.

Goffaux, V., \& Rossion, B. (2006). Faces are "spatial"-Holistic face perception is supported by low spatial frequencies. Journal of Experimental Psychology: Human Perception and Performance, 32, 1023-1039.

Goldstein, E. B. (1999). Sensation and perception. Pacific Grove, CA: Brooks/Cole.

Goren, D., \& Wilson, H. R. (2006). Quantifying facial expression recognition across viewing conditions. Vision Research, 46, 1253-1262.

Gratton, G., Coles, M. G. H., \& Donchin, E. (1983). A new method for offline removal of ocular artifact. Electroencephalogram Clinical Neurophysiology, 55, 468-484.

Halit, H., de Haan, M., Schyns, P. G., \& Johnson, M. H. (2006). Is high-spatial frequency information used in the early stages of face detection? Brain Research, 1117, 154-161.

Hammarrenger, B., Leporél, F., Lippé, S., Labrosse, M., Guillemot, J. P., \& Roy, M. S. (2003). Magnocellular and parvocellular developmental course in infants during the first year of life. Documenta Ophthalmologica, 107, 225-233.
Henson, R. N., Goshen-Gottstein, Y., Ganel, T., Otten, L. J., Quayle, A., \& Rugg, M. D. (2003). Electrophysiological and haemodynamic correlates of face perception, recognition and priming. Cerebral Cortex, 13, 793-805.

Hess, R. F. (2004). Spatial scale in visual processing. In L. M. Chalupa \& J. S. Werner (Eds.), The visual neurosciences (pp. 1043-1059). Cambridge, MA: MIT Press.

Holmes, A., Green, S., \& Vuilleumier, P. (2005). The involvement of distinct visual channels in rapid attention towards fearful facial expressions. Cognition and Emotion, 19, 899-922.

Holmes, A., Winston, J. S., \& Eimer, M. (2005). The role of spatial frequency information for ERP components sensitive to faces and emotional facial expression. Cognitive Brain Research, 25, 508-520.

Hsiao, F. J., Hsieh, J. C., Lin, Y. Y., \& Chang, Y. (2005). The effects of face spatial frequencies on cortical processing revealed by magnetoencephalography. Neuroscience Letters, 380, 54-59.

Jacques, C., \& Rossion, B. (2004). Concurrent processing reveals competition between visual representations of faces. Neuroreport, 15, 2417-2421.

Jacques, C., \& Rossion, B. (2006). The speed of individual face categorization. Psychological Science, 17, 485-492.

Johnson, M. H. (2005). Subcortical face processing. Nature Reviews Neuroscience, 6, 766-774.

Kotsoni, E., de Haan, M., \& Johnson, M. H. (2001). Categorical perception of facial expressions by 7-month-old infants. Perception, 30, 1115-1125.

Laycock, R., Crewther, S. G., \& Crewther, D. P. (2007). A role for the magnocellular advantage in visual impairments in neurodevelopmental and psychiatric disorders. Neuroscience and Biobehavioral Reviews, 31, 363-376.

Le Doux, J. E. (1996). The emotional brain. New York: Simon \& Schuster.

Leppänen, J. M., Moulson, M. C., Vogel-Farley, V. K., \& Nelson, C. A. (2007). An ERP study of emotional face processing in the adult and infant brain. Child Development, 78, 232-245.

Luck, S. J. (2005). An introduction to the event-related potential technique. Cambridge, MA: MIT Press.

McCarthy, G., Puce, A., Belger, A., \& Allision, T. (1999). Electrophysiological studies of human face perception II: Response properties of face specific potentials generated in occipitotemporal cortex. Cerebral Cortex, 9, 431444.

McCleery, J. P., Zhang, L., Ge, L., Wang, Z., Christiansen, E. M., Lee, K., et al. (2008). The roles of visual expertise and visual input in the face inversion effect: Behavioral and neurocomputational evidence. Vision Research, 48, 703-715.

Mihaylova, M., Stomonyakov, V., \& Vassilev, A. (1999). Peripheral and central delay in processing high spatial frequencies: Reaction time and VEP latency studies. Vision Research, 39, 699-705.

Morison, V., \& Slater, A. (1985). Contrast and spatial frequency components in visual preferences of newborns. Perception, 14, 345-348. 
Morrison, D. J., \& Schyns, P. G. (2001). Usage of spatial scales for the categorization of faces, objects, and scenes. Psychonomic Bulletin \& Review, 8, 454-469.

Morton, J., \& Johnson, M. H. (1991). CONSPEC and CONLERN: A two-process theory of infant face recognition. Psychological Review, 98, 164-181.

Musselwhite, M. J., \& Jeffreys, D. A. (1985). The influence of spatial frequency on the reaction times and evoked potentials recorded to grating pattern stimuli. Vision Research, 25, 1545-1555.

Nelson, C. A., \& de Haan, M. (1996). Neural correlates of infants" visual responsiveness to facial expressions of emotion. Developmental Psychobiology, 29(7), 577-595.

Nelson, C. A., \& Dolgin, K. (1985). The generalized discrimination of facial expressions by 7 -month-old infants. Child Development, 56, 58-61.

Nobre, A. C., Rao, A., \& Chelazzi, L. (2006). Selective attention to specific features within objects: Behavioral and electrophysiological evidence. Journal of Cognitive Neurocience, 18, 539-561.

Parr, L. A., \& Heintz, M. (2008). Discrimination of faces and houses by rhesus monkeys: The role of stimulus expertise and rotation angle. Animal Cognition, 11, 467474.

Peltola, M. J., Leppänen, J. M., Mäki, S. M., \& Hietanen, J. K. (2009). Emergence of enhanced attention to fearful faces between 5 and 7 months of age. Social Cognitive and Affective Neuroscience, 4, 134-142.

Pourtois, G., Dan, E. S., Grandjean, D., Sander, D., \& Vuilleumier, P. (2005). Enhanced extrastriate visual response to bandpass spatial frequency filtered fearful faces: Time course and topographic evoked-potentials mapping. Human Brain Mapping, 26, 65-79.

Pourtois, G., Grandjean, D., Sander, D., \& Vuilleumier, P. (2004). Electrophysiological correlates of rapid spatial orienting towards fearful faces. Cerebral Cortex, 14, 619633.

Reichenbach, L., \& Masters, J. C. (1983). Children's use of expressive and contextual cues in judgements of emotion. Child Development, 54, 993-1004.

Rossion, B., Campanella, S., Gomez, C. M., Delinte, A., Debatisse, D., Liard, L., et al. (1999). Task modulation of brain activity related to familiar and unfamiliar face processing: An ERP study. Clinical Neurophysiology, 110, 449-463.

Schyns, P. G., \& Oliva, A. (1999). Dr. Angry and Mr. Smile: When categorization flexibly modifies the perception of faces in rapid visual presentations. Cognition, $69,243-265$.

Skottun, B. C., \& Skoyles, J. R. (2007). A few remarks on relating reaction time to magnocellular activity. Journal of Clinical and Experimental Neuropsychology, 29, 860-866.

Slater, A., \& Sykes, M. (1977). Newborn infants' visual responses to square wave gratings. Child Development, $48,545-554$.
Spreen, O., \& Strauss, E. (1998). A compendium of neuropsychological tests: Administration, norms and commentary. New York: Oxford University Press.

Stekelenburg, J. J., \& de Gelder, B. (2004). The neural correlates of perceiving human bodies: An ERP study on the body-inversion effect. Neuroreport, 15, 777-780.

Taylor, M. J. (2002). Non-spatial attentional effects on P1. Clinical Neurophysiology, 113, 1903-1908.

Taylor, M. J., Batty, M., \& Itier, R. J. (2004). The faces of development: A review of early face processing over childhood. Journal of Cognitive Neuroscience, 16, 14261442.

Tellegen, P. J., Winkel, M., Wijnberg-Williams, B. J., \& Laros, J. A. (1998). Manual and justification of the SON-R 2.5-7. Göttingen, Germany: Hogrefe-Verlag.

Thomas, K. M., Drevets, W. C., Whalen, P. J., Eccard, C. H., Dahl., R. E., Ryan, N. D., et al. (2001). Amygdala response to facial expressions in children and adults. Biological Psychiatry, 49, 309-316.

Tottenham, N., Borscheid, A., Ellertsen, K., Marcus, D. J., \& Nelson, C. A. (2002). Categorization of facial expressions in children and adults: Establishing a larger stimulus set. Journal of Cognitive Neuroscience, S74.

Tottenham, N., Hare, T. A., \& Casey, B. J. (2009). A developmental perspective on human amygdala function. In E. Phelps \& P. Whalen (Eds.), The human amygdala. (pp. 107-118). New York: Guilford.

Valdes-Sosa, M., Bobes, M. A., Rodriguez, V., \& Pinilla, T. (1998). Switching attention without shifting the spotlight: Object-based attentional modulation of brain potentials. Journal of Cognitive Neuroscience, 10, 137-151.

Viggiano, M. P., Righi, S., \& Galli, G. (2006). Categoryspecific visual recognition as affected by aging and expertise. Archives of Gerontology and Geriatrics, 42, 329338.

Vlamings, P. H. J. M., Goffaux, V., \& Kemner, C. (2009). Is the early modulation of brain activity by fearful facial expressions primarily mediated by coarse low spatial frequency information? Journal of Vision, 9, 1-13.

Vuilleumier, P., Armony, J. L., Driver, J., \& Dolan, R. J. (2003). Distinct spatial frequency sensitivities for processing faces and emotional expressions. Nature Neuroscience, 6, 624-631.

Wechsler, D. (1991). Wechsler Intelligence Scale for Children-Third Edition. Manual. San Antonio: Psychological Corporation.

Williams, L. M., Liddell, B. J., Rathjen, J., Brown, K. J., Gray, J., Phillips, M., et al. (2004). Mapping the time course of nonconscious and conscious perception of fear: An integration of central and peripheral measures. Human Brain Mapping, 21, 64-74.

Winston, J. S., Vuilleumier, P., \& Dolan, R. J. (2003). Effects of low-spatial frequency components of fearful faces on fusiform cortex activity. Current Biology, 13, 1824-1829. 